MATEC Web of Conferences 25, 04008 (2015)

DOI: $10.1051 /$ matec conf/ 20152504008

(C) Owned by the authors, published by EDP Sciences, 2015

\title{
Cleaning Process Research of MVR High Concentration Salty Wastewater Treatment System
}

\author{
Na Wang \& Wenqiang Jiang \\ School of Environmental Science and Engineering, Qilu University of Technology, Jinan, Shandong, China \\ Libin Fang \\ Water Technology Research Institute, A Agrochemical Company of Binzhou, Binzhou, Shandong, China
}

\begin{abstract}
A mechanical vapor re-compression (MVR) evaporation system for the treatment of the highly-concentrated inorganic salt wastewater was investigated, and its process characteristics were analyzed taking sodium chloride salt wastewater as the treated solution. In this paper, by adding " $\mathrm{H}_{2} \mathrm{O}_{2}$ oxidation + filter + flash evaporation + hot filter" technology on the basis of original traditional MVR treatment system, the optimum technological conditions were determined through the experiment: The $\mathrm{pH}$ value is 8.5 ; the oxidation time is $24.0 \mathrm{~h} ; \mathrm{H}_{2} \mathrm{O}_{2}$ amount accounting for $1 \%$ of the total wastewater under the condition of outlet test MVR system respectively fell $88.5 \%$ and $90.1 \%$ than the traditional process of effluent COD and NH3-N removal rate. MVR system for the sodium chloride salt qualified rate was increased from $83.2 \%$ to $98.2 \%$. On the other hand, this process avoided the highly-concentrated outside of mother liquor by flashing evaporation recycling volatile solvent; the optimization process results were found to be consistent with published practical industrial data. Compared with the new process MVR system, the operation load of MVR system was lower. Therefore, the system can be used to treat the highly-concentrated inorganic salt wastewater and save energy. Therefore, the cleaning process can achieve remarkable energy saving and consumption, and reduce the pollution and the pollution and environmental protection effect.
\end{abstract}

Keywords: high-concentrated salty wastewater; MVR system; cleaning process

\section{INTRODUCTION}

High-concentrated salty (inorganic salt) wastewater is a form of pollution which is difficult to treat. It is generated in numerous industrial sectors, and the discharge of such wastewater without prior treatment will pollute the environment ${ }^{[1-3]}$. In particular, wastewater that contains dissolved salts (namely contains $\mathrm{Cl}^{-}$, $\mathrm{SO}_{4}^{2-}, \mathrm{Na}^{+}, \mathrm{Ca}^{2+}$, etc.) could be recycled if these salts are directly discharged. Hence, the treatment and recovery of such wastewater are necessary. At present, these types of wastewater are usually treated using evaporation techniques, such as multi-stage flash (MSF), multi-effect evaporator (MEE) and reverse osmosis (RO) methods. Among them, MEE is considered to be more effective than other processes ${ }^{[4,5]}$. However, the MEE method requires a large amount of external heating vapor, the system and its operation are complex [6]. So the mechanical vapor re-compression (MVR) is an alternative method for the treatment of high-concentrated salty wastewater in numerous chemical enterprises.

Although the MVR system has been widely studied, it has not been widely applied in wastewater process. The MVR system used in the wastewater distillation with reliable and long-term operation is limited in China ${ }^{[7]}$. One of the most pressing problems is the absence of design optimization process. Therefore, the purposes of this study were to develop a comprehensive design cleaning process of the effective mechanical vapor compression process, and to analyze the performances focusing on the salt content, discharge conditions of mother liquor and the solvent recovery by flashing technology.

The design processes of the MVR high concentrated salty wastewater treatment system are important parts in actual production or research. In this study, the factors that influence the mechanical vapor compression system are discussed more comprehensively. The influencing factors include the accumulation of organic matter in the heater, and the organic solvent waste water which cannot be recycled and so on Moreover, the performance of the system was investigated through using sodium chloride salt wastewater. The following sections include a description of the optimized process, the determination of experimental conditions of the system and an analysis of the system.

\section{PROCESS DESCRIPTION AND PROCESS IM-} PROVEMENT

\subsection{Present situation of the enterprise production wastewater}

According to the actual survey, when the pesticide chemical plant is in the process of production prepara- 


\section{MATEC Web of Conferences}

tion, the amount of its wastewater emission is about 423.6 tons a day in 2014. And the high-concentrated salty wastewater is about a third of the total discharge quantity. This part of the wastewater mainly contains methanol, toluene, ethanol, acetonitrile, sodium chloride, macromolecular heterocyclic reaction by-products and so on. The wastewater appears to be red, containing pharmaceutical intermediates. It is a kind of typical refractory wastewater. The main pollutants include residual polyethylene monomer by polymerization and all kinds of polymerization additives such as dispersant, initiator, termination agent and reaction and decay products and so on. The water quality is as follows: COD is as high as $20000-35000$ $\mathrm{mg} / \mathrm{L}$, among which the $\mathrm{NH} 3-\mathrm{N}$ is in the range of $626-1260 \mathrm{mg} / \mathrm{L}$, the $\mathrm{pH}$ value is in the range of 5.0 6.5 and the $\mathrm{NaCl}$ salt content is more than $18 \%$.

High-concentrated salty wastewater refers to the total waste water containing inorganic salt mass fraction which is more than $3.5 \%{ }^{[8,9]}$. The distillation-based water treatment is a conventional technology in the field of wastewater treatment, especially in the process of high salinity wastewater treatment, which contains salts with $\mathrm{Cl}^{-}, \mathrm{SO} 4{ }^{2-}, \mathrm{Na}^{+}, \mathrm{Ca}^{2+}$ and the mass concentration which is more than $1 \%{ }^{[10,11]}$. The existence of a large amount of salt can lead to the bacteria cell wall dehydration. Practice has proved that when the content of $\mathrm{Cl}^{-}$in water is more than $15 \mathrm{~g} / \mathrm{L}$, the biochemical process becomes very difficult, and the concentration of $\mathrm{Cl}^{-}$is $14-16 \mathrm{~g} / \mathrm{L}$ in enterprises' wastewater production. If we continue to increase the content of $\mathrm{Cl}^{-}$, the biochemical processes is very bad, so we must remove the salts in the wastewater in advance in order to improve the effect of biochemical means. These types of wastewaters are usually treated using evaporation techniques. The characteristic of MVR is the reuse of the energy of vapor produced in the evaporator. And the efficiency of MVR is higher than that of MSF and $\mathrm{MEE}^{[12]}$

Our government attaches great importance to the development of MVR wastewater treatment technology, and has put the technology into the national strategic emerging industries. "The complete recycling for zero discharge water vapour recompression crystallization" project has been listed as the "National Strategic Technology Plan for Newly-emerged Industry by the Support of Chinese Academy of Sciences" in one of the themes of energy conservation and environmental protection industries ${ }^{[13]}$. Our government has provided policy and project investment guarantee to establish the domestic independent research and development of MVR crystallization recovery system engineering research platform, and the development of industrial wastewater MVR zero emissions crystal full recovery technology.

Recently, the MVR system is mainly used in the process of high salinity wastewater treatment. Matsuda et al. ${ }^{[14]}$ used the actual operation data of the treatment process in a heavy chemical industrial field as an industrial application, and the initial feasibility study was undertaken by applying energy conserva- tion and environmental protection from an industrial point of view.

\subsection{MVR before optimization processing system}

The sewage in the workshop storage tanks is staged 12 days later by the pump into the sewage transfer tank. Two reconcile the tanks can be alternately used every other day in order to make the sewage mix even. Reconciling the tank is mainly to add liquid alkali $\mathrm{pH}$ adjustment. The liquid is filtrated and then into the MVR system. Then after becoming concentrated crystallization in MVR system, it will be concentrated into the centrifuge and directly recycled into reconciled tanks away from the mother liquor. Finally, the concentration of salt crystals will be regarded as a product for sale. We steam out of the condensate to send to the sewage treatment station after Fenton oxidation into biochemical treatment. The specific process is expressed in Figure 1.

As the previous description, the MVR system can precipitate $\mathrm{NaCl}$ crystals from the wastewater and quantitative water into the Fenton oxidation and biochemical treatment. Therefore, this system is environmentally friendly. Recently, this kind of MVR system has been mainly used in the process of salt crystals. The major part of literature study of the MVR system is the crystallization of ammonium sulfate ${ }^{[15]}$ sodium chloride ${ }^{[16]}$ and other salts. However, this MVR is not an energy-saving choice for the treatment of high-concentrated salty wastewater if the previously described single-effect MVR system is used. Under certain conditions the mother liquor recycled, the chromaticity of the centrifuged salt increases as the organics of mother liquor increases. At the same time, the higher liquor organics leads to higher power consumption to maintain the heat-transfer temperature difference. Therefore, a certain number of liquor circulation needs to be quantitatively discharged in order to maintain the quality of salt. The main problems are divided into four aspects about the MVR system in high-concentrated salty wastewater treatment process, and the main problems are presented as follows:

(1) The solvent content in the wastewater becomes more and more, and the solvent content of being more than $10 \%$ will subsequently lead to the multi-effect evaporation steamed effluent COD which becomes high, thus affecting water quality of subsequent pretreatment effluent.

(2) Salt content in the waste water was larger. And the mixed wastewater including sodium chloride, potassium chloride and organic halogen contains salt after evaporation, causing multi-effect evaporation at the scene of the salt. Small amounts of workshop intermediates, whose appearance is grey and red-brown organic impurities, are unable to deal with. They can only become waste.

(3) After the mother liquor of high-concentrated wastewater which is separately discharged through using four-effect evaporator concentrate is processed, the treated wastewater is incorporated by low concen- 


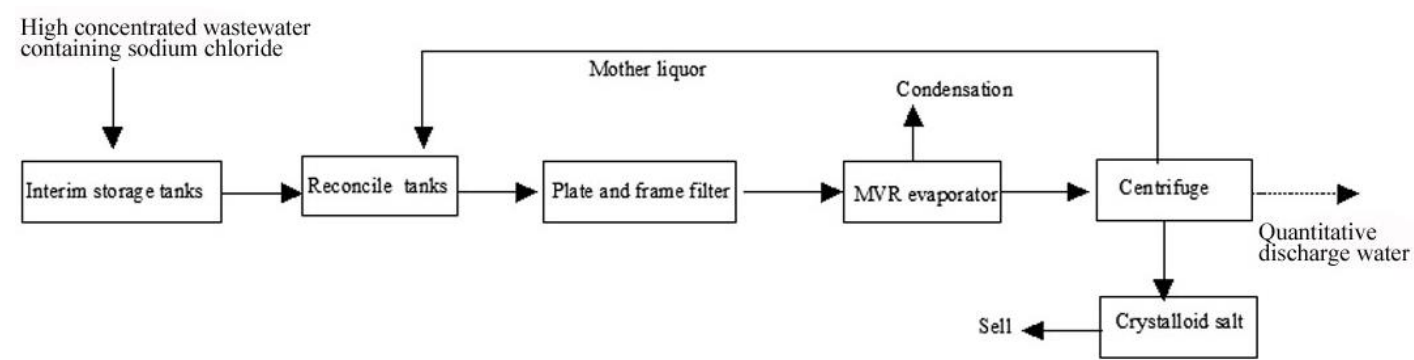

Figure 1. MVR before optimization processing system

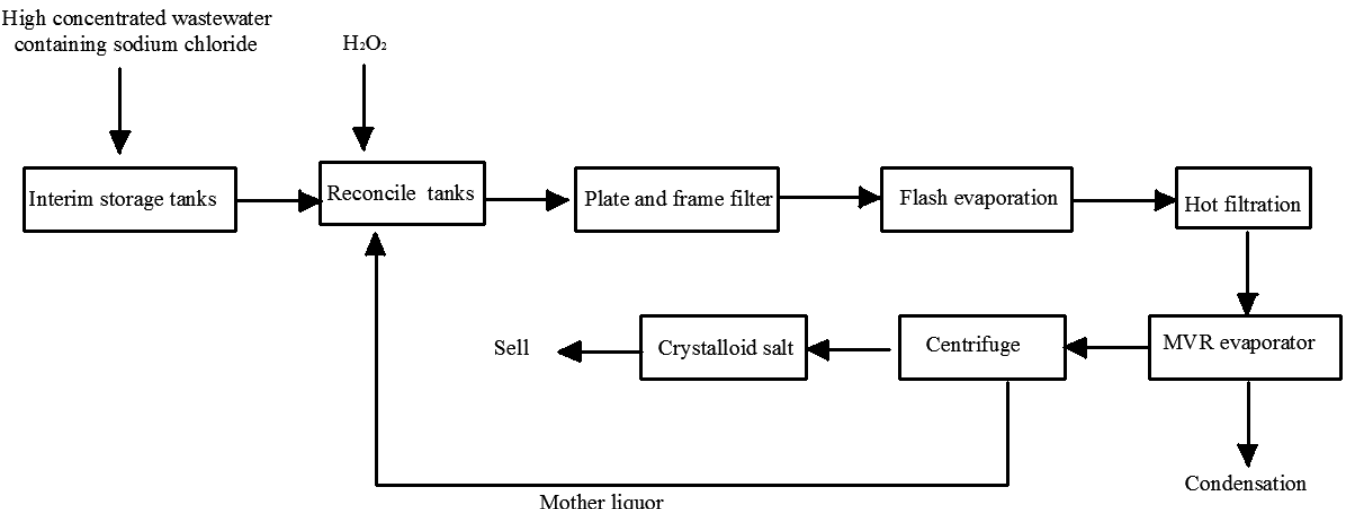

Figure 2. MVR optimized processing system

tration waste water treatment processes. However, in the process of high-strength wastewater, the main problem is that the high solvent content causes the multi-effect evaporator scaling phenomenon to be more serious, affecting the amount of change heat treatment. What's worse, more waste oil and tar-like substances can cause blockage of multi-effect evaporator heat exchanger tube.

So it is necessary to optimize the traditional process from the aspect of process technology. Liang, et al. ${ }^{[17]}$ reported on the MVR evaporation method of saline wastewater treatment process. Yu Haichen, et al. ${ }^{[18]}$ thoroughly investigated the improved MVR process to improve the efficiency of wastewater treatment. In addition, they found that MVR can be combined with other systems such as MSF ${ }^{[19-22]}$ and MEE ${ }^{[21-23]}$ systems.

\subsection{MVR optimized processing system}

According to the above defects and considering the salt chromaticity which is the accumulation of organic matter in the heater, the final decision is that adding " $\mathrm{H}_{2} \mathrm{O}_{2}$ oxidatio + filter + flash evaporation +hot filter" technology. The operation is simple, and it can greatly reduce the energy consumption. After being optimized, the high salt wastewater treatment process is shown in Figure 2 .
The building of the MVR optimized processing system is based on the relation of energy saving, consumption and reduction of pollution and efficiency in each part of the system. Compared with the actual working conditions, the processing system reaches a good desired effect: (1) zero discharge of mother liquid of high-concentrated organic impurities; (2) recycling salt chromaticity drop, and the salt content which is over $95 \%$ has reached the delivery requirements; (3) a large part of the solvents are recycled after fully utilization, and it simultaneously reduces the evaporator MVR system operation load, hence greatly reducing the company operation cost. Therefore, this system is environmentally friendly.

\section{THE CHOICE OF OPTIMUM CONDITION}

\subsection{Optimum $\mathrm{H}_{2} \mathrm{O}_{2}$ dosage and reaction time}

In the workshop, we take 4 groups of $500 \mathrm{~mL}$ high-concentrated salty wastewater samples, and the measured water quality is as follows: $22027.04 \mathrm{mg} / \mathrm{L}$ $\mathrm{COD}, 671.6 \mathrm{mg} / \mathrm{L} \mathrm{NH}-\mathrm{N}, \mathrm{pH} 8.5$, including our $22 \%$ of sodium chloride salt, and the methanol accounting for $23.7 \%$ in total. Then according to the proportion of $5 \mathrm{~L}, 10 \mathrm{~L}, 15 \mathrm{~L}$ and $20 \mathrm{~L}$ water which are added to $\mathrm{H}_{2} \mathrm{O}_{2}$, those reactions which are respectively for $2.0 \mathrm{~h}, 4.0 \mathrm{~h}$, 


\section{MATEC Web of Conferences}

$6.0 \mathrm{~h}, 8.0 \mathrm{~h}$ and 24 hours under the condition of $\mathrm{pH} 8.5$ are simultaneously evaporated out of salt. The experimental results are shown in Figures 3 and 4:

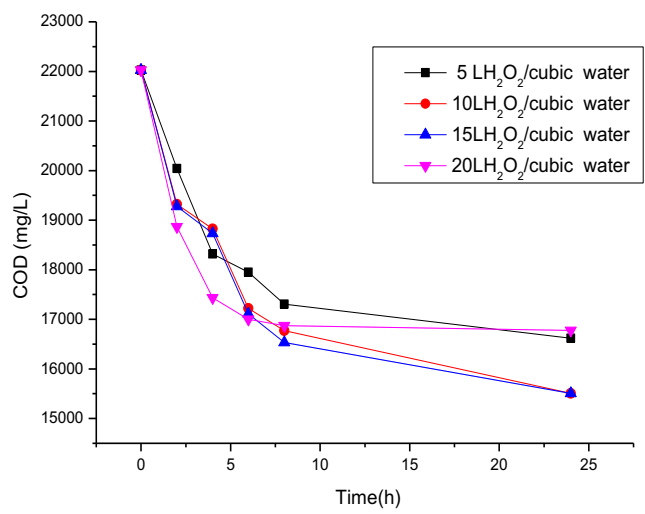

Figure $3 . \mathrm{H}_{2} \mathrm{O}_{2}$ dosage and reaction time on the influence of the waste water COD

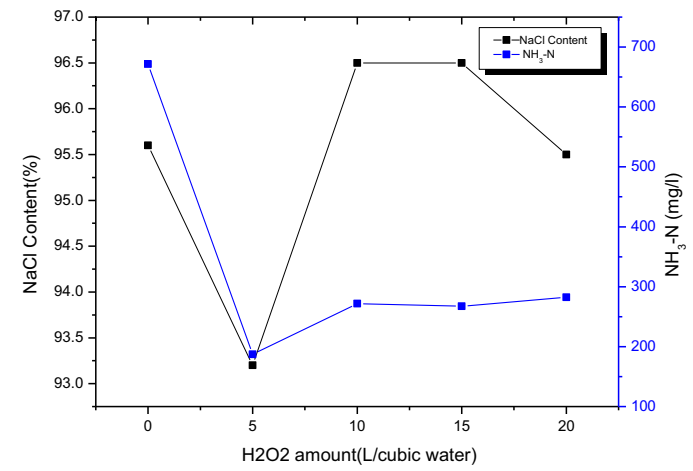

Figure 4. $\mathrm{H}_{2} \mathrm{O}_{2}$ amount of influence on the $\mathrm{NH}_{3}-\mathrm{N}$ and salt content

Figure 3 shows the results for the influence of the waste water $\mathrm{COD}$ on account of $\mathrm{H}_{2} \mathrm{O}_{2}$ dosage and reaction time. As being also evident in Figure 3, the waste water COD has a certain degree of being reduced with the increase of the reaction time. The degradation of waste water $\mathrm{COD}$ and $\mathrm{NH}_{3}-\mathrm{N}$ rate is increased as the response time increases, and the amount of $\mathrm{H}_{2} \mathrm{O}_{2}$ is $10 \mathrm{~L} ; 15 \mathrm{~L} /$ water COD degradation rate is highest and the qualified rate of salt is the best. As shown in Figure 5, the influence of $\mathrm{H}_{2} \mathrm{O}_{2}$ amount on the $\mathrm{NH}_{3}-\mathrm{N}$ and salt content is evident when the amount of hydrogen peroxide under different conditions is added. The figure can be easily found that the sodium chloride salt content is peaked when the amount of hydrogen peroxide is $10 \mathrm{~L} /$ cubic water. So it is optimum to choose the $\mathrm{H}_{2} \mathrm{O}_{2}$ amount which is $10 \mathrm{~L}$ $\mathrm{H}_{2} \mathrm{O}_{2}$ /cubic water. And the longer the reaction time is, the better the effect can be. It can be judged according to the color and turbidity of water, and it needs to react for at least 8 hours. However, considering the two which reconcile the tanks can be alternately used together, so the reaction time we choose is 24 hours.

\subsection{Optimum $p H$ value conditions}

For the same sample, according to the proportion, 10L $\mathrm{H}_{2} \mathrm{O}_{2}$ /cubic water under the condition of $\mathrm{pH} 5.5,6.5$, $7.5,8.5,9.5$ and 10.0 respectively responses in 24 hours. After the flash process and MVR treatment, we compare the reaction condition, and the experimental results are shown in Figure 5:

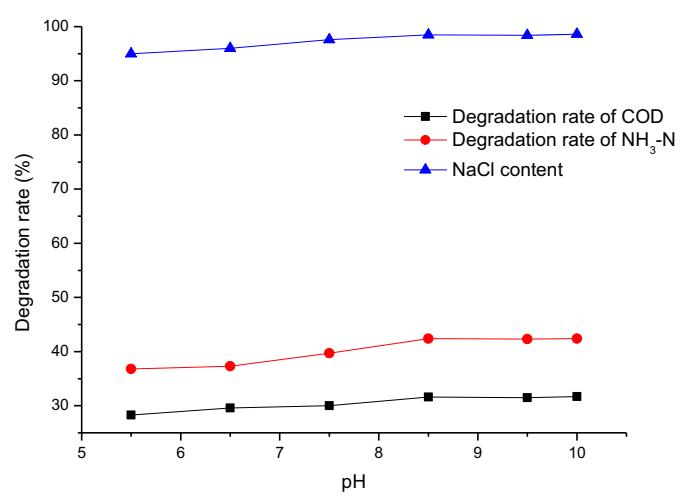

Figure 5. Degradation rate versus the oxidation reaction at different $\mathrm{pH}$ value condition

Figure 5 shows the degradation rate versus the oxidation reaction at different $\mathrm{pH}$ value condition. The $\mathrm{pH}$ value condition is respectively chosen from 5.5 to 10. It can be seen from Figure 3 that the degradation rate is slightly increased with the increase of $\mathrm{pH}$ value. The results also show that it is similar to the hydrogen peroxide treatment effect under the condition of acid and alkaline conditions, but the effect of reaction under condition of alkaline reaction is slightly better than the effect of acid condition. Through the comparison of the color salt and COD reduction rate and the comprehensive consideration of color in water sample, we choose to directly add the hydrogen peroxide to do oxidation processing under alkaline conditions. Then we can find that there are a lot of flocs when mother liquor reacts with hydrogen peroxide under the alkaline condition. And it can be used to neutralize acidic waste water and won't make cost rise. Therefore, reaction $\mathrm{pH}$ value we choose is 8.5 .

\subsection{Influence of adding flash device for waste water} treatment

The raw water is filtered into the flash system after oxidation, and then we control the flash system according to the different solvents with different control temperature by $1-3 \%$ of the distillate water. The flash water contains light component (this topic is to steam 
EMME 2015

Table 1. Adding flash system for wastewater treatment effect

\begin{tabular}{llllll}
\hline $\begin{array}{l}\text { Monitoring } \\
\text { point }\end{array}$ & State & $\mathrm{COD}(\mathrm{mg} / \mathrm{L})$ & $\mathrm{NH}_{3}-\mathrm{N}(\mathrm{mg} / \mathrm{L})$ & $\begin{array}{l}\mathrm{NaCl} \text { con- } \\
\text { tent of the } \\
\text { first out }(\%)\end{array}$ & $\begin{array}{l}\mathrm{NaCl} \text { content after } 35 \text { times } \\
\text { reuse of mother liquor }(\%)\end{array}$ \\
\hline Raw water & Raw water tanks & 15506.40 & 327.2 & -- & -- \\
& Without flash before & 15506.40 & 327.2 & -- & -- \\
MVR inlet & After add the flash & 9020.42 & 96.74 & -- & -- \\
\multirow{2}{*}{$\begin{array}{l}\text { MVR } \\
\text { outlet }\end{array}$} & Without flash before & 12783.62 & 236.22 & 83.2 & 67.2 \\
& After add the flash & 1472.22 & 23.46 & 98.2 & 96.2 \\
\hline
\end{tabular}

out of methanol), and the $\mathrm{pH}$ value of adjusted water is neutral. A large number of free ammonia exhalations are steamed out with light component, which enter the MVR system's content is reduced. Therefore, even the centrifugal mother liquor which was repeatedly reused will also not affect the quality of salt; what's more, it can greatly reduce the high concentrated emission of mother liquor at the same time. The specific test results are shown in Table 1.

According to the results of calculation and analysis above, after adding flash system, it can not only recover solvents but also make the MVR import water COD and $\mathrm{NH}_{3}-\mathrm{N}$ be respectively reduced by $41.83 \%$ and $70.4 \%$. Meanwhile, the effluent $\mathrm{COD}$ and $\mathrm{NH}_{3}-\mathrm{N}$ MVR system were respectively reduced by $88.5 \%$ and $90.1 \%$ than before without flash. It can also greatly reduce the operation load of MVR evaporation system at the same time. Also, it can be seen that the centrifugal $\mathrm{NaCl}$ salt content is above from $80 \%$ to $98 \%$ at the first time, but salt quality of mother liquor stay above $95 \%$ for several times. So it can avoid the mother liquor to be discharged in order to maintain the quality of the salt. The literature shows that the flash system can achieve higher energy efficiency than that of the conventional processes.

\section{CONCLUSION}

A comprehensive optimization process is developed to overcome the problems in traditional MVR system in practical production. The overall $\mathrm{pH}$ value condition, response time and oxidant dosage were given in the optimization process. The performance of the system was investigated using high salinity wastewater containing $\mathrm{NaCl}$. This process by adding " $\mathrm{H}_{2} \mathrm{O}_{2}$ oxidation + filter + flash evaporation + hot filter" technology is on the basis of originally traditional MVR treatment system, and the optimum technological conditions were determined through the experiment: The $\mathrm{pH}$ value is 8.5 ; the oxidation time is $24.0 \mathrm{~h} ; \mathrm{H}_{2} \mathrm{O}_{2}$ amount accounting for $1 \%$ of the total wastewater under the condition of outlet test MVR system respectively fell $88.5 \%$ and $90.1 \%$ than the traditional process of effluent $\mathrm{COD}$ and $\mathrm{NH}_{3}-\mathrm{N}$ removal rate. The MVR system is used for the sodium chloride salt qualified rate which is increased from $83.2 \%$ to $98.2 \%$. On the other hand, this process can avoid the high concentrated outside of mother liquor by flashing evaporation recy- cling volatile solvent. The optimization process results were found to be consistent with practical industrial data which was published. Compared with the new process MVR system, the operation load of MVR system was lower.

The experimental and practical industrial data indicated that the optimized MVR system is more energy-conserving and environmentally-friendly than traditional system when they are used to treat sodium chloride wastewater. It can not only effectively improve the clean production level of this company, but also have a very important practical guiding significance for the high-concentrated salty wastewater treatment of chemical enterprise.

\section{REFERENCES}

[1] G. Parthasarathy, \& R.F. Dunn, 2004. Graphical strategies for design of evaporation crystallization networks for environmental wastewater applications, Adv. Environ. Res. 8: 247-265.

[2] A. Fakhru'l-Razi, A. Pendashteh, L.C. Abdullah, D.R.A. Biak, S.S. Madaeni, \& Z.Z. Abidin, 2009. Review of technologies for oil and gas produced water treatment. Hazard. Mater.170: 530-551.

[3] L. Di Palma, N. Verdone, A. Chianese, M. Di Felice, C. Merli, E. Petrucci, \& G. Veriani, 2002. Treatment of wastewater with high inorganic salts content, Environ. Eng. Sci. 19: 329-339

[4] O. Lefebvre, \& R. Moletta, 2006. Treatment of organic pollution in industrial saline wastewater: a literature review, Water Res. 40 3671-3682.

[5] D.F. Zhao, J.L. Xue, S. Li, H. Sun, \& Q.D. Zhang, 2011. Theoretical analyses of thermal and economical aspects of multi-effect distillation desalination dealing with high salinity wastewater, Desalination 273:292-298.

[6] Lin Liang, Dong Han, Ran Ma, \& Tao Peng, 2013. Treatment of high-concentration wastewater using double-effect mechanical vapor recompression, Desalination 314: 139-146.

[7] Yasu Zhou, Chengjun Shi, \& Guoqiang Dong, 2014 Analysis of a mechanical vapor recompression wastewater distillation system, Desalination 353: 91-97.

[8] Woolard C R, \& Irvine R L. 1995. Treatment of hypersaline wastewater in the sequencing batch reactor. Water Research, 29: 1159-1168.

[9] Shaomei Nong, Handong Li, \& Shuzeng Zhang, et al. 2007. Treatment technology research progress of hyper- 


\section{MATEC Web of Conferences}

saline wastewater. Jiangsu Environment. 21(2008) 72-76 (in Chinese).A.A. Mabrouk, A.S. Nafey, H.E.S. Fath, Thermoeconomic analysis of some existing desalination processes, Desalination 205: 354-373.

[10]X. Zhao, \& W. Li, et al., 2011.Suppression of liquid film rupture during falling film evaporation for high salinity wastewater, J. Environ. Eng. 5: 726-730 (in Chinese).

[11]Q. Xie, Y.H. Li, \& Y.N. Zhu, 2004. Study on biological treatment process of high salinity wastewater, Environ. Eng. 22: 15-17 (in Chinese).

[12]F.N. Alasfour, \& H.K. Abdulrahim, 2011.The effects of stage temperature drop on MVC thermal performance, Desalination 265: 213-221.

[13]Guoxiao Li, \& Liping Lu, 2013. MVR marinating al alkali run summary, China Chlor-Alkali (4)10-12.

[14]K. Matsuda, K. Kawazuishi, \& Y. Hirochi, 2010. Advanced energy saving in the reaction section of the hydro-desulfurization process with self-heat recuperation technology, Appl. Therm. Eng. 30: 2300-2306.

[15] Jian Wang. 1999. The impact of WTO on China's organic silicon industry. Silicone materials and applications, 1-3(in Chinese).

[16]D. G. Nicola, 2001.Sol-Gel-Derived Silicon-Boron Oxycarbide Glasses Containing Mixed Silicon Oxycarbid (SiCxO4-x) and Boron Oxycarbide (BCyO3-y) Units. $J$. Am. Ceram. Soc, 2160-2164.
[17] Liag L, Han D, \& Ma R, et al. 2013.Treatment of hign concentration wasterwater using double - effect mechanical vapor recompression. Desalination, 314 139-146.

[18]Haichen Yu, Peiwen Zhong, \& Wei Gao, et al. 2013. Zero Discharge Process Design and Synthesis of Chemical high salt wastewater. Urban Environment \& Urban Ecology. 26: 44-46(in Chinese)

[19]F.N. Alasfour, \& H.K. Abdulrahim, 2011. The effects of stage temperature drop on MVC thermal performance, Desalination 265: 213-221.

[20] A.A. Mabrouk, A.S. Nafey, \& H.E.S. Fath, 2007. Analysis of a new design of a multi-stage flash-mechanical vapor compression desalination process, Desalination 204:482-500.

[21]A.A. Mabrouk, A.S. Nafey, \& H.E.S. Fath, 2007. Thermoeconomic analysis of some existing desalination processes, Desalination 205:354-373.

[22] A.S. Nafey, H.E.S. Fath, \& A.A. Mabrouk, 2006. A new visual package for design and simulation of desalination processes, Desalination 194: 281-296.

[23]A.S. Nafey, H.E.S. Fath, \& A.A. Mabrouk, 2008. Thermoeconomic design of a multi-effect evaporation mechanical vapor compression (MEE-MVC) desalination process, Desalination 230: 1-15. 